\title{
Effect of counseling on secure bonding among domestically abused women with unintended pregnancy
}

\author{
Niven R. Basyouni ${ }^{1}$, Mariam M. Kawafha ${ }^{2}$ \\ ${ }^{1}$ Assistant Professor of Obstetrics and Gynecologic Nursing, Faculty of Nursing, Alexandria University/ Egypt \\ ${ }^{2}$ Associate Professor of community health Nursing, Faculty of Nursing-Irbid National University / Jordan
}

\begin{abstract}
Purpose: This study has examined the effect of counseling on secure bonding among domestically abused women with an unintended pregnancy.

Methods: This interventional study was conducted at two randomly selected Maternity Educational Hospitals, one in Egypt and the other in Jordan. An instrument was developed by the investigators based on previous literature consisting of two sections: demographic and obstetric data and Observational checklist to Assess Secure Bonding.

Results: One hundred and thirteen women completed the study, of whom 56 (49.5\%) were from Egypt and 57 (50.4\%) were from Jordan. There was a high statistically significant difference between the Egyptian experimental and control groups on secure bonding post intervention (x2 is 8.02. The p-value is .05). Likewise, there was a highly statistically significant difference between the Jordanian study and control group on secure bonding after intervention ( $x 2$ is 4.25 . The p-value is .04). Also, significant association was found between the experimental and the control groups in both countries $(p=.00)$.

Conclusion: The counseling affected positively mother's secure bonding. Counseling on bonding should be part of nursing activities during the prenatal care, with special attention to domestically abused women with an unintended pregnancy.
\end{abstract}

Keywords: Counseling, Domestic Violence, Maternal-Child Relations.

\section{Introduction}

Domestic abuse is a violent conduct, offence or perversion from a family member not in favor of another. It could be in the form of physical, sexual, emotional and economic abuse (Johnson, 2015).

Domestic abuse seems to be a worldwide issue. Approximations propose that in global one from each three women have suffered either bodily or sexual exploitation from a spouse. Unfortunately this attitude of aggression in opposition to women and girls remain tremendously high (WHO, 2014).

Although its augmented recurrence and serious effects on health and wellbeing; spouse abuse against women is not up till now supposed an important issue In Arab or Islamic world (Douki et al, 2003). Results from Middle East revealed that not less than one in three surveyed women are battered by her partner (Fageeh, 2014.). Dramatically, one-third of women in Egypt have been actually harmed by their husbands and seven percent said they are beaten "often" (EDHS, 2005) Alexandria, the second-largest Egyptian city, revealed higher levels of partner violence, with almost seventy five percent of attendant to family health centers have been victimized to husband's violence in their life (Ibrahim et al, 2010). Research in Jordan implies that roughly one out of four women has reported bodily violence (Nasser, Belbeisi \& Atiyat, 2000). A survey carried out in Zarqa, the third-largest city in Jordan, also designated major levels of domestic abuse. For instance, hitting with the hand occurred often or always in around one quarter of the surveyed population (Jordan Population and Family Health Survey, 2002). Generally, this picture indicates that domestic violence has high prevalence in the Arab world, although estimates are speculative due to most victimized women suffering in a "culture of silence," largely related to the fact that partner hostility is viewed as a confidential issue and a permissible response to misconduct by woman.

Although pregnancy is particularly a risky period in the health of a woman, this consideration fails to inhibit violence against women. Indeed, data suggests a significant relationship among incidence of intimate partner abuse and unplanned pregnancy (Oweis, Gharaibeh \& Alhourani, 2010).

Women who suffer domestic abuse during pregnancy are more insecurely bonded and emotionally involved to their babies than others (Clementina Pires de Almeida et al 2013). Previous studies have established that without doubt unintended pregnancy impacts physical and mental health, as well as cognitive outcomes and a less close mother-child relationship (Crissey, 2006; David, 2006; Ispa et al, 2007). 
The effect of counseling on secure bonding among domestically abused women with unintended..

Significance of the study

Many researchers have dealt with domestic abuse during pregnancy, focusing on its prevalence, risk factors, and consequences. Although maternity nurses play a unique and important role in motivating and assisting women's healthy behavior, scarce research has addressed this issue, thus this study examines the effect of counseling on secure bonding among domestically abused women with unintended pregnancy.

\section{Material and Methods}

Aim

This study aimed to explore the effect of counseling on secure bonding among domestically abused women with unintended pregnancy

Design

Posttest-Only Research was utilized to investigate the impact of counseling on secure bonding among the target population.

Sample

A purposive sampling technique was used in collecting the data. The theoretical population of this study was women suffering from domestic violence who had unintended pregnancy. The accessible population was a purposeful sample of unintended and victimized pregnant women in Egypt and Jordan, the largest in the north of the Middle East countries. The researchers approached women during their pregnancy and followed them until the first month post-partum in order to cover the antenatal and postnatal periods, from the former of which mothers generally begin to develop strong bonds towards their infants.

The current study sample comprised of women without medical conditions, aged 20 to 35 years, with low risk pregnancy. Primi-gravida participated voluntarily in this study during their first trimester was supposed to have completed full-term and normal delivery with a single viable fetus. The aim of these inclusion criteria was to avoid confounding variables. All women in the study group were surveyed initially having unintended pregnancy and suffering from domestic violence.

The sample magnitude was counted using $\mathrm{G}^{*}$ power software (Faul et al, 2007). The average effect size was requested for the aim of the current study. It was calculated to be 0.5 . The sample bulk was specified consistent with the power level. It was 0.80 for independent samples $t$ test, and conventional $\alpha=0.05$ two-tailed test was used for the significant relation. Accordingly, 55 women were desired. To avoid the problem of attrition, a supplementary five women were increased to have 60 in the last sample dimension from each country. Each national cohort (i.e. Egyptian and Jordanian) was further subdivided randomly to both the study and the control group, each of which had 30 participants.

Setting

This interactional research was accomplished at a two randomly selected Maternity Educational Hospitals, one in Egypt and the other in Jordan. These hospitals were the largest educational hospitals specialized in maternity, obstetrics and gynecology in both countries, so they have large population densities. In addition, they are attended by women with similar socio-economic status, which guarantees the homogeneity of the study sample.

Tools:

Two tools were used in this study, as follows.

Tool I:

Socio- demographic and reproductive data structure interview schedule.

This tool was designed and used by the researchers to collect data about the subjects' general characteristics such as age, level of education, as well as their reproductive history and current pregnancy characteristics include last menstrual period, expected date of delivery and gestational age. This section was answered through interview.

Tool II:

\section{Observational Checklist to Assess Secure Bonding}

This tool was adapted from (Moullin, Waldfogel \& Washbrook, 2014). Assaying Behaviors of secure bonding manifest through; mother; response to infants' crying, changing voice tone when talking to or about the baby, engaging in face to face contact with the neonate, demonstrating the ability to comfort the baby, enjoy close physical contact and initiate positive interactions with the baby, and identify positive qualities in the newborn. Secure bonding is most clearly displayed in natural reactions to the neonate most of the time demonstrating warmth, alertness and quickness of response, such as picking up, carrying and reassuring the 
The effect of counseling on secure bonding among domestically abused women with unintended..

baby when crying. Accordingly the researchers assessed whether the mothers exhibited the above mentioned behaviors to determine secure bonding, where (1) if yes she demonstrated the behavior and (0) if not.

The researchers appreciated breast feeding, baby bathing and baby clothing as an excellent opportunity to assess all these qualities (Andreassen \& West, 2007).

\section{Methods:}

\section{The intervention domestic abuse counseling program}

The counseling program was reviewed by five specialists in obstetric and gynecologic, community and psychiatric nursing to evaluate the content and sufficiency of the knowledge presented to the women enrolled in the study. The interference was suitable for all women in the study groups, and no modification was required for the intercession to be adapted to the individual woman.

The intervention domestic abuse counseling program, which was expected to result in secure bonding between mothers and neonates, was presented by the researchers (interventionist) to the women (recipients) in the two experimental Egyptian and Jordanian groups. Providing adequate counseling can promote connection, which can itself be a soothing activity that includes a sense of encouragement connected to mothers' internal experience of attachment and secure bonding.

The study was conducted in three phases:

\section{A--Pre assessment phase:}

The researcher screens all pregnant women meet the eligible criteria, consecutive sample was solicited. Then they were individually interviewed by the researcher to collect the basic data using (tool 1) and randomly assigned to either study (30) or control (30) group.

\section{B-The implementation phase:}

The counseling program contained two themes, the first of which was health education and knowledge about breast feeding, baby bathing and baby clothing (Bowden \& Greenberg, 2011). The second comprised four strategies: increasing direct eye contact; maximizing touch activities (combing or brushing baby's hair, giving back or foot rubs, holding and cuddling the baby daily); getting warm and cozy by holding the baby in a warm blanket, putting the baby in a sleeping bag on the bed and sharing a lap robe while watching the TV; and creative activities, whereby mothers were asked to be purposeful to make life fun and build memories (Ohio Child Welfare Training Program, 2005).

The interference held through a four monthly sessions. These sessions have been set up in the meeting rooms of the previously chosen hospitals. All themes of the counseling agenda were enclosed. Each meeting lasted roughly one hour. Group counseling-based interventions were delivered to all women in the study groups. The researchers adopted group discussions, pictures and videos presentations as well as demonstration and role play. During counseling sessions, the researchers asked the participants to share ideas, express feelings and support each other.

At the last session ending the professional rapport, a closing session was held to summarize all the strategies discussed. CDs and hand-outs were distributed to each participant.

\section{C-The evaluation phase:}

The post-test observational checklist to Assess Secure Bonding was performed for the sum of experimental and control groups while their first post-partum visits.

\section{Data Collection Procedures and Ethical Considerations}

Before the conduction of this study an official permission was obtained from the responsible authorities of the study settings to take their permission to conduct the study.

Consequently, once permission was granted to proceed with the fieldwork, the researchers also approached the directors of the selected settings to elucidate the aim and methods of the research and to obtain their cooperation. Also, a simple explanation of the research aim was given by researchers to the study subjects to obtain their cooperation and participation. The participants were assured of anonymity and that the information will be used for scientific research only, and will be strictly confidential. The participants were informed that they are permitted to remove from participation any time they wish. The study subjects were asked to give their consent before any data compilation.

To get the required number of study entrants $(n=60)$, researchers attained the selected hospitals two times a week throughout the morning shift and accessed all women with the enclosure criteria through the study time. Data were collected throughout the period from June 2014 to January 2015. Data collection was accomplished by means of interviews, examination and participant observation.

The Egyptian and Jordanian control groups received the routine hospital care. The study groups from both countries received the counseling program under the orientation and close observation of the researchers. The number of entrants in the Egyptian experimental group was 27 and control group was 29. The Jordanian experimental grouping consisted of 29 women and the control group contained 28 women. 
The women interviewed were blinded to their group appointments, except the researchers recognized this information while conducting interviews. Women were familiar of their group before counseling implementation. Maintaining respondent's privacy for each woman in all groups was assured through a code number prearranged for each participant. Researchers were responsible for interviewing the women, completing the tools and applying the counseling program.

No precise arrangements were done prior to the intervention; except that the researchers attempted to decide suitable times for the women to accomplish the counseling sessions. No indemnifications were given to the participants. Researchers who carried out the counseling program have doctoral qualification and were educated and trained enough to perform counseling and moderating groups.

\section{Data Analysis}

SPSS software edition 20 was used for statistical analysis of the collected data. One sample t-test between percentages and Chi square (x2) test were attempted to check whether there was any statistical significant relationship between the study and control groups in term of secure bonding. $P$ value at $<0.05$ was believed to be significant.

\section{Results}

Sixty female unintended pregnancy victimized to domestic abuse were selected from the two national groups at the baseline. The volunteers from each country were separately further randomly allocated to either the control or experimental group, thus thirty participants were at the control or experimental group. Table (1) illustrates the socio-demographic and obstetric profile of the study sample. Major proportion of the participants was aged 26 to 30 years $(63.3 \%$ \& $76.7 \%)$ for the Egyptian experimental and control groups, respectively. For the Jordanian groups, two thirds of the experimental group (66.6\%) and approximately three-quarters of the control group (73.4\%) corresponded to the same age cohorts, respectively. About $63.3 \%$ and 56.6\% from Egypt experimental and control populations and $60 \%$ and $53.3 \%$ of the corresponding Jordanian groups had secondary education. For education, $26.7 \%$ of the experimental and $36.7 \%$ of the control group in Egypt had a bachelor's degree, compared to $36.7 \%$ each for the Jordanian groups. The great majority of experimental and control groups in both countries were working (83.3\% \& 90\% for Egypt and 80\% \& $70 \%$ for Jordan) respectively. Monthly income for Egyptian participants ranged from \$175-\$714, while for Jordanian participants it ranged from \$290-\$1350. No significant difference was found between the Egyptian and Jordanian study sample in relation to socio-demographic data, where $(\mathrm{x} 2=9.15 . \mathrm{p}=.42, \mathrm{X} 2=4.94 . \mathrm{p}=.84 \& \mathrm{x} 2=4.03$. $\mathrm{p}=.26)$ for age, education and occupation correspondingly.

Participants comprised a total of 113 women, of whom 56 (49.56\%) were from Egypt and 57 (50.44\%) were from Jordan. For the Egyptian population, 27 were enrolled in the experimental group and 29 in the control group. More than three quarters $(81.5 \%)$ of the Egyptian experimental group demonstrated secure bonding behaviors compared to less than half $(44.8 \%)$ of the control group. A high statistically significant differentiation was found between the Egyptian experimental and control groups on secure bonding behaviors post-intervention ( $\mathrm{x} 2$ is 8.02 . The $p$-value is .00). Table (2)

In the meanwhile, 29 women joined to the Jordanian experimental group and the control one contained 28 participants. $79.3 \%$ of the Jordanian experimental group compared to $53.6 \%$ of the control group had secure bonding. Likewise, the Jordanian experimental group differed statistically from the control group on secure bonding after interference ( $\mathrm{x} 2$ is 4.25 . The $p$-value is .04). Table (3)

Furthermore, the study results suggested statistical significant variation among the two Egyptian and Jordanian experimental groups on one side and the sum of Egyptian and Jordanian control groups on the other side (x2=12.05, $\mathrm{p}=.00)$. Table (4).

\section{Discussion}

The current study found that the counseling positively affected mothers' secure bonding. This result is supported by Elsinga et al. (2008), who indicated that after pre-conceptual counseling, a sizable proportion of women significantly varied their conduct to diminish unfavorable pregnancy outcomes. Furthermore, Rollnick et al. (2002) found that counseling encourages clients to make their own decisions about behavior (e.g. secure bonding).

The researchers in this study appreciated a great opportunity to practice secure bonding behaviors while providing baby care such as breast feeding, clothing and baths. This is congruent with Liu et al. (2014), who found that breast feeding is coupled with several advantages related to the health and wellbeing of both infants and their mothers and might upgrade maternal-infant attachment. However this may be not contributed to the type of feeding itself but it could be related to the quality of the maternal-infant relationship.

Moullin et al. (2014) demonstrated that secured bonding established through responsive and receptive caring during the early years of life. The current study agreed with this point of view; as it illuminated that the 
experimental groups had secured bonding significantly different to that of those in the control groups. This was investigated in this research within and between two countries, Egypt and Jordan. This finding is congruent with the result of preceding studies (Berlin, 2005; Berlin et al, 2008; Murray, 2003) showing that parental counseling improves secure bonding, and gives more secure early maternal-infant interaction.

Moreover, the current study result is consistent with a research conducted in Australia revealed that, mothers perceived a program to teach them to build a constructive and reactive bond with their infants as to be highly beneficial by the maternal participants (Tsivos et al, 2015).

The present study and the previous research cited above concur with the idea that behavioral aspects of secure attachment and bonding assisted by counseling. This finding in contrast with Feldman et al. (2007) and Levine et al. (2007), who attributed secure bonding to the hormone Oxytocin. However researchers have been running overtime to discover the Oxytocin's role in regulating maternal behavior. Oxytocin is connected to such activities as lactation, bonding and sexual enjoyment; said Tori DeAngelis, (2008) and Taylor, (2006). On the other hand, it was obvious that the experiential effects of Oxytocin are not consistently favorable; where the inter-personal factors adjust the effects of Oxytocin (Olff 2013). In fact Oxytocin appears to have path; as real or expected bonding may result in bursts of Oxytocin and vise versa; which again highlights the effect of counseling on such maternal behavior as secure bonding.

\section{Conclusion}

In conclusion, this study supports the efficacy of counseling program among domestically abused women with unintended pregnancy in Egypt and Jordan and significantly increasing secure bonding between mothers and their newborns. The implications of this study highlight the importance of supporting domestically abused women with unintended pregnancy through their antenatal period so that they practice secure bonding that newborns need for optimal growth development.

\section{Recommendations}

The researchers thus recommend that secure bonding counseling should be a part of nursing activities during the prenatal care that maternity nurses provide, with special attention to domestically abused women with unintended pregnancy.

\section{References}

[1]. Andreassen Carol and West Jerry (2007). Measuring socioemotional functioning in a national birth cohort study. Infant Mental Health Journal. 28, (6), 627-646.

[2]. Berlin, L. (2005). Interventions to Enhance Early Attachment. In Berlin L., Ziv Y., Jackson L. Amaya, \& Greenberg M., Enhancing Early Attachments: Theory, Research, Intervention, and Policy. New York: The Guilford Press, pp. 3-34.

[3]. Berlin, L., Cassidy, J., \& Appleyard, K. (2008). The Influence of Early Attachments on Other Relationships. In Cassidy, J. \& Shaver, P (eds.) Handbook of Attachment: Theory, Research, Clinical Applications. New York: Guilford Press.

[4]. Bowden, Vicky R. and Greenberg, Cindy Smith. (2011). Pediatric Nursing Procedures. Third edition LWW co. Philadelphia.

[5]. Clementina, Pires de Almeida, Eduardo, Sá, Flávia Cunha. \& Ermelinda, P. Pires. (2013). Violence during pregnancy and its effects on mother-baby relationship during pregnancy. Journal of Reproductive and Infant Psychology, 31(4), 370-380.

[6]. Crissey, S. (2006). Effect of pregnancy intention on child well-being and development: Combining retrospective reports of attitude and contraceptive use. Population Research and Policy Review, 24(6), 594-615.

[7]. David, H. P. (2006). Born unwanted, 35 years later: The Prague study. Health Matters, 14(27), 181-190.

[8]. Douki, S., Nacef, F., Belhadj, A., Bouasker. A. \& Ghachem, R. (2003). Violence against women in Arab and Islamic countries. Archives of Women's Mental Health, 6 (3), 165-171.

[9]. Elsinga, J., de Jong-Potjer, LC. Van der Pal-de., Bruin, KM., le Cessie, S. Assendelft, WJ., Buitendijk, SE. (2008). The effect of preconception counseling on lifestyle and other behavior before and during pregnancy. Journal of Women's Health Issues, 18 (6), $117-125$.

[10]. El-Zanaty, and Associates. Demographic and Health Survey (2005). Ministry of Health and Population. Cairo, Egypt.

[11]. Fageeh, M. K. Wafa. (2014). Factors associated with domestic violence: a cross-sectional survey among women in Jeddah, Saudi Arabia. BMJ, 4(2).

[12]. Faul, F., Erdfelder, E., Lang, A., \& Buchner, A. (2007). G*Power 3: A flexible statistical power analysis program for the social, behavioral, and biomedical sciences. Behavior Research Methods, 39, 175-191.

[13]. Feldman, R., Weller, A., Zagoory-Sharon, O., et al. (2007). Evidence for a neuro-endocrinological foundation of human affiliation Plasma oxytocin levels across pregnancy and the postpartum period predict mother-infant bonding, Psychological Science, 18(11), 965-970.

[14]. Ibrahim, F. Khrboush, Farzaneh, Roudi-Fahimi, Hanaa, M. Ismail, Heba, M. Mamdouh, Yasmine, Y. Muhammad, May, M. Tawfik, Omnia, G. EL sharkawy, and Hassan, N. Sallam. (2010) Spousal Violence in Egypt. Retrieved April 2015 from www.prb.org

[15]. Ispa, J. M., Sable, M. R., Porter, N., \& Csizmadia, A. (2007). Pregnancy acceptance, parenting stress, and toddler attachment in low-income black families. Journal of Marriage and Family, 69(1), 1-13.

[16]. Johnson, Andy J. (2015). Religion and Men's Violence Against Women. New York. Springer-Verlag.

[17]. Jordan Population and Family Health Survey (JPFHS). (2002). Summary and recommendation of the population and family health survey.Amman, Jordan

[18]. Levine, A., Zagoory-Sharon. O., Feldman, R. et al. (2007). Oxytocin during pregnancy and early postpartum: individual patterns and maternal-fetal attachment. Journal of Peptides,28(6), 1162-1169.

[19]. Liu, J. Leung, P. and Yang, A. (2014). Breastfeeding and Active Bonding Protects against Children's Internalizing Behavior Problems. Journal of Nutrients; 6(1): 76-89 
The effect of counseling on secure bonding among domestically abused women with unintended..

[20]. Moullin, S., Waldfogel, J. and Washbrook, E. (2014). Baby Bonds Parenting, attachment and a secure base for children. Improving social mobility through education. Retrieved April 2015 from http://www.suttontrust.com/wp-content/uploads/2014/03/baby-bondsfinal.pdf.

[21]. Murray, L., Cooper, PJ., Wilson, A., Romaniuk, H., (2003) Controlled trial of the short- and long-term effect of psychological treatment of post-partum depression: 2. Impact on the mother-child relationship and child outcome. Br J Psychiatry. 182,420-7

[22]. Nasser, L., Belbeisi, B., \& Atiyat, D. (2000). Violence against women in Jordan: Demographic characteristics of victims and perpetrators. The Human Forum for Women's Rights. Amman: Jordan Press Foundation.

[23]. Ohio child welfare training program. (2005). Activity Handout Understanding and Building Attachment. Retrieved 14 March, 2014, from: http://www.ocwtp.net/PDFs/Trainee\%20Resources/Fundamentals/attachment\%20Handouts.pdf

[24]. Olff Miranda, Jessie L. Frijling, Laura D. Kubzansky, Bekh Bradley, Mark A. Ellenbogen, Christopher Cardoso, Jennifer A. Bartz, Jason R. Yee, Mirjam van Zuiden. (2013). The role of Oxytocin in social bonding, stress regulation and mental health: An update on the moderating effects of context and interindividual differences. Journal of Psycho-neuro-endocrinology, 38 (9), 1883 - 1894.

[25]. Oweis, A., Gharaibeh, M. \& Alhourani, R. (2010). Prevalence of Violence during Pregnancy: Findings from a Jordanian Survey. Maternal Child Health J, 14:437-445

[26]. Rollnick, S. Allison, J., Ballasiotes, S., Barth, T., Butler, C., Rose, G. and Rosengren, D. (2002) Variations on a Theme: Motivational Interviewing and its Adaptations In: Miller, WR. \& Rollnick, S. Motivational interviewing: Preparing people for change. $2^{\text {nd }}$ ed. New York: Guilford Press. pp. 270-283.

[27]. Taylor. (2006). Tend and Befriend Bio-behavioral Bases of Affiliation under Stress. Current Directions in Psychological Science.15 (6), 273-277.

[28]. Tori DeAngelis. (2008). The two faces of Oxytocin. American psychological association, 39 (2), 30

[29]. Tsivos Zoe-Lydia, Calam Rachel, Sanders Matthew R, and Wittkowski Anja. (2015). Interventions for postnatal depression assessing the mother-infant relationship and child developmental outcomes: a systematic review. J Womens Health. 7: $429-447$.

[30]. WHO. (2014). International Day for the Elimination of Violence Against Women. Geneva: World Health Organization.

Table 1: Socio-demographic and obstetric data of Egyptian and Jordanian participants $(\mathrm{n}=120)$

\begin{tabular}{|c|c|c|c|c|}
\hline \multirow[t]{2}{*}{ Variable } & \multicolumn{2}{|l|}{$\begin{array}{l}\text { Jordan } \\
(n=60)\end{array}$} & \multicolumn{2}{|l|}{$\begin{array}{l}\text { Egypt } \\
(n=60)\end{array}$} \\
\hline & $\begin{array}{l}\text { Control } \\
N=30 \\
N(\%)\end{array}$ & $\begin{array}{l}\text { Experimental } \\
N=30 \\
N(\%)\end{array}$ & $\begin{array}{l}\text { Control } \\
N=30 \\
N(\%)\end{array}$ & $\begin{array}{l}\text { Experimental } \\
N=30 \\
N(\%)\end{array}$ \\
\hline \multicolumn{5}{|l|}{ Age } \\
\hline$<20$ & $1(3.3 \%)$ & $2(6.7 \%)$ & $1(3.3 \%)$ & None $(0.0 \%)$ \\
\hline $21-25$ & $4(13.3 \%)$ & $3(10 \%)$ & $3(10.0 \%)$ & $9(30.0 \%)$ \\
\hline $26-30$ & $22(73.4 \%)$ & $20(66.6 \%)$ & $23(76.7 \%)$ & $19(63.3 \%)$ \\
\hline $31-35$ & $3(10.0 \%)$ & $5(36.7 \%)$ & $3(10.0 \%)$ & $2(6.7 \%)$ \\
\hline \multicolumn{5}{|l|}{ Education } \\
\hline$<$ Secondary & $2(6.7 \%)$ & $1(3.3 \%)$ & $2(6.7 \%)$ & $3(10 \%)$ \\
\hline Secondary & $16(53.3 \%)$ & $18(60.0 \%)$ & $17(56.6 \%)$ & $19(63.3 \%)$ \\
\hline Bachelor's & $11(36.7 \%)$ & $11(36.7 \%)$ & $11(36.7 \%)$ & $8(26.7 \%)$ \\
\hline Postgraduate & $1(3.3 \%)$ & None $(0.0 \%)$ & None $(0.0 \%)$ & None $(0.0 \%)$ \\
\hline \multicolumn{5}{|l|}{ Occupation } \\
\hline Working & $21(70.0 \%)$ & $24(80.0 \%)$ & $27(90.0 \%)$ & $25(83.3 \%)$ \\
\hline Not working (housewife) & $9(30.0 \%)$ & $6(20.0 \%)$ & $3(10.0 \%)$ & $5(36.7 \%)$ \\
\hline
\end{tabular}

Table (2) Distribution of the Egyptian study sample $(n=56)$ according to demonstrating secure bonding behaviors

\begin{tabular}{|c|l|l|l|}
\hline Secure bonding behaviors & $\begin{array}{l}\text { Egyptian Experimental group } \\
(\mathrm{n}=27)\end{array}$ & $\begin{array}{l}\text { Egyptian } \\
\text { Control group } \\
(\mathrm{n}=29)\end{array}$ & P value \\
\hline$\bullet \quad$ Yes & $22(81.5 \%)$ & $13(44.8 \%)$ & \multirow{2}{*}{$* 0.00$} \\
\hline$\bullet \quad$ No & $5(18.5 \%)$ & $16(55.2 \%)$ & $\mathrm{P}=.00$ \\
\hline
\end{tabular}

*This result is significant at $p<.05$

Table (3) Distribution of the Jordanian study sample $(n=57)$ according to demonstrating secure bonding behaviors

\begin{tabular}{|c|c|c|c|}
\hline Secure bonding behaviors & $\begin{array}{l}\text { Jordanian Experimental group } \\
(\mathrm{n}=29)\end{array}$ & $\begin{array}{l}\text { Jordanian } \\
\text { Control group } \\
(\mathrm{n}=28)\end{array}$ & P value \\
\hline - $\quad$ Yes & $23(79.3 \%)$ & $15(53.6 \%)$ & \multirow[b]{2}{*}{$* \mathrm{P}=.04$} \\
\hline • $\quad \mathrm{No}$ & $6(20.7 \%)$ & $13(46.4 \%)$ & \\
\hline
\end{tabular}

*This result is significant at $p<.05$

Table (4) Distribution of the Egyptian and Jordanian study groups $(n=113)$ according to demonstrating secure bonding behaviors

\begin{tabular}{|c|l|l|l|}
\hline Secure bonding behaviors & $\begin{array}{l}\text { Egyptian and Jordanian } \\
\text { Experimental group } \\
(\mathrm{n}=56)\end{array}$ & $\begin{array}{l}\text { Egyptian and Jordanian } \\
\text { Control group } \\
(\mathrm{n}=57)\end{array}$ & P value \\
\hline$\bullet \quad 45(80.4 \%)$ & $28(49.1 \%)$ & $* \mathrm{P}=.00$ \\
\hline$\bullet \quad 11(19.6 \%)$ & $29(50.9 \%)$ & \\
\hline
\end{tabular}

*This result is significant at $p<.05$ 